\title{
Effect of MAG welding on microstructure and mechanical properties of dual phase steel
}

\author{
S. Ulu ${ }^{1}$, M. Cakmakkaya ${ }^{2}$, S. Talas ${ }^{1}$ \\ ${ }^{1}$ Afyon Kocatepe University, Faculty of Technology, Metallurgical and Materials Engineering, \\ Afyonkarahisar 03200, Turkey \\ ${ }^{2}$ Afyon Kocatepe University, Faculty of Technology, Automotive Engineering, Afyonkarahisar 03200, Turkey
}

Received 3 Februay 2014, received in revised form 30 April 2014, accepted 2 May 2014

\begin{abstract}
In this study, the effect of metal active gas (MAG) welding has been evaluated on the microstructural and mechanical properties of dual phase steel. Low carbon dual phase steels containing varying volume fraction of martensite was produced with coarse and fine microstructure. Specimens were joined by MAG welding method and tensile tests and microstructural analysis were performed on these specimens. Initial microstructure of steel plates appears to be a factor in determining the microstructure of heat affected zone (HAZ). Average grain size in MAG weld metal deposited on fine grained dual phase steels produced was in the range of 7.7 to 8.9 micron. Columnar grains with comparatively large average grain size were also observed in weld metals. Yield and maximum tensile strengths are relatively lower than those of non welded steels. Tensile strengths of weld metals (WM) deposited on initially coarse grained dual phase steels yielded better results than those with initially fine grained dual phase steels.
\end{abstract}

K e y w o r d s: dual phase (DP) steel, metal active gas (MAG) welding, microstructure, mechanical properties

\section{Introduction}

Increasing environmental concern and fuel prices motivate car manufacturers to use lightweight materials having a higher tensile strength coupled with better ductility. By reducing the weight of a car less fuel consumption along with less $\mathrm{CO}_{2}$ emission can be achieved [1]. A recent research in Europe showed that the use of advanced high strength steel (AHSS) could reduce the weight of automobile by $25 \%$. Dual-phase (DP) steel is one of the most common AHSS steels [2]. The microstructure of DP steels consists of islands of martensite in the ferrite matrix with or without the presence of retained austenite where the martensite accounts for strength and the ferrite is responsible for ductility [3-6]. Usually DP steels are produced by intercritical annealing followed by a rapid cooling $[7,8]$. During the intercritical annealing treatment small pools of austenite are formed in the ferrite matrix, which subsequently transform to martensite upon rapid cooling. Compared with high strength low alloy (HSLA) steels, DP steel shows slightly lower yield strength but the continuous flow behaviour in DP steel results in larger and also more uniform total elongation and higher initial work hardening rate along with considerably higher ultimate tensile strength [9-12]. All these satisfactory mechanical characteristics have made DP steel attractive to the automobile manufacturers [10]. MAG has great importance to automobile industry for car body. Good weld quality cannot only insure the car body security and reliability, but also influence the accuracy of car assembly [13].

The MIG (metal inert gas)/(MAG) welding is an arc welding process in which additional metal is brought by a roll of wire line and is molten by an electric arc [14]. It is used extensively by the sheet metal industry and, by extension, the automobile industry. There, the method is often used for arc spot welding, thereby replacing riveting or resistance spot welding. It is also popular for automated welding, in which ro-

*Corresponding author: tel.: +90 272 2281446; fax: +90 272 2281449; e-mail address: $\underline{\text { sinanulu@aku.edu.tr }}$ 
Table 1. The chemical composition (wt.\%) of the St37

\begin{tabular}{ccccccccccc}
\hline \multirow{2}{*}{ Steel } & \multicolumn{10}{c}{ Elements } \\
\cline { 2 - 12 } & $\mathrm{C}$ & $\mathrm{Mn}$ & $\mathrm{Cr}$ & $\mathrm{Ni}$ & $\mathrm{P}$ & $\mathrm{S}$ & $\mathrm{Si}$ & $\mathrm{Al}$ & $\mathrm{Cu}$ & $\mathrm{N}$ \\
\hline St37 & 0.073 & 0.64 & 0.049 & 0.065 & 0.01 & 0.004 & 0.206 & 0.053 & 0.075 & 0.027 \\
\hline
\end{tabular}

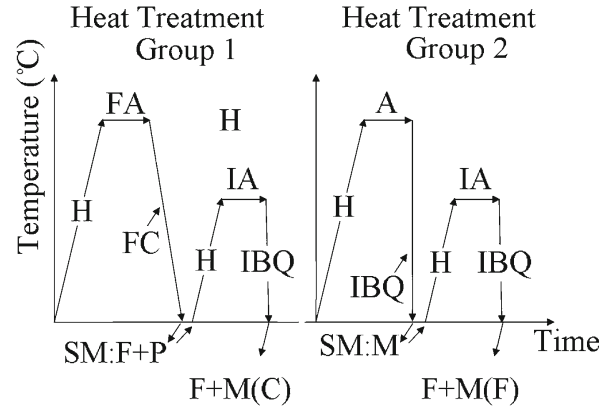

Fig. 1. Graphical representation of heat treatments applied to steels prior to welding (FA: full annealing $\left(900^{\circ} \mathrm{C}\right), \mathrm{A}$ : austenitizing $\left(900^{\circ} \mathrm{C}\right)$, IA: intercritical annealing, IBQ: ice brine quenching, SM: starting microstructure, $\mathrm{F}+\mathrm{P}$ : ferrite + pearlite, $\mathrm{M}$ : martensite, $\mathrm{C}$ : coarse and $\mathrm{F}$ : fine, $\mathrm{H}$ : heating rate of $20^{\circ} \mathrm{C} \mathrm{min}^{-1}$ and cooling rate for IBQ is $\left.2160{ }^{\circ} \mathrm{C} \mathrm{s}^{-1}\right)$.

bots handle the work pieces and the welding gun to speed up the manufacturing process [15].

In this study, St37 structural steel was used. Structural steels are used in many applications, combining good welding properties with guaranteed strengths. There are many grades and the uses varied including civil and industrial engineering. HSLA steels have replaced many structural steels where weight reduction is important (e.g., automotive) but with guaranteed strengths. St37 steels were subjected to intercritical heat treatment to produce coarse and fine grained steel with martensite + ferrite structures. Welded and non welded specimens containing 30, 50 and 80 vol. $\%$ of martensite were also tested for mechanical characterization and microstructures were examined.

\section{Experimental procedures}

\subsection{Material}

The structural steel St37 was used in this study and its composition was determined by using Foundry-Master Xpert spectrometer of Oxford Instruments. The chemical composition of structural steel St37 is given in Table 1.

\subsection{Heat treatments and metallography}

Strips of steel were prepared and heat treatment was performed in a bench top box furnace. A summary of all heat treatments carried out is shown in Fig. 1. Two groups of heat treatments were performed on the specimens. In the first heat treatment the specimens were cooled in the furnace after full annealing and then intercritical annealing was given to the specimens at varying temperatures which was followed by quenching into ice brine in order to obtain ferrite + martensite structure in coarse grain. The second type of heat treatment involved austenitizing which was followed by the ice brine quenching and then intercritical annealing was performed prior to second ice brine quenching again in order to obtain ferrite + martensite microstructure in fine grain. The intercritical annealing temperatures were chosen between 720 and $850^{\circ} \mathrm{C}$. In short, after the starting microstructures were obtained, the specimens were given intercritical annealing at temperatures of $720,730,740,750,760,770$, $780,790,800,810,820,830,840$ and $850^{\circ} \mathrm{C}$.

The annealing heat treatment was $30 \mathrm{~min}$ in argon shroud and ice brine temperature was approximately $5^{\circ} \mathrm{C}$. Full annealing and austenitizing temperature was selected as $900^{\circ} \mathrm{C}$. Following the observations of microstructure, specimens containing martensite volume fractions of 30, 50 and $80 \%$ were welded by MAG technique. Standard metallographic techniques were employed for microstructural observations before which a surface layer of $0.2 \mathrm{~mm}$ was removed in order to eliminate decarburized part of the specimens. All specimens were ground and polished to 1 micron surface finish. A 3 vol.\% Nital $+10 \%$ sodium metabisulphite solution was used to etch the specimens prior to optical microscopy. Volume fraction of each phase was determined by commercial software, MicroCAM 4.1, and the grain sizes were determined by linear intercept method (ASTM E112-12). After pre-heat treatments in Fig. 1, selected experimental parameters were coded as in Fig. 2.

\subsection{MAG welding parameters and tensile test}

Table 2 shows MAG welding parameters used in this study. SG2 filler metal with a composition of low alloy steel was purchased from Askaynak welding company, Turkey.

Dimensions of specimens prior to welding and the direction and location where tensile test specimens were extracted on the welded specimens are also given in Fig. 3. 
Ta ble 2. MAG welding parameters

\begin{tabular}{ccccc}
\hline Welding speed $\left(\mathrm{mm} \mathrm{s}^{-1}\right)$ & Current $(\mathrm{A})$ & Wire speed $\left(\mathrm{mm} \mathrm{s}^{-1}\right)$ & Gas & Wire code \\
\hline 1.5 & 165 & 10 & $\mathrm{CO}_{2}$ & SG2 \\
\hline
\end{tabular}

Table 3. Change of obtained martensite volume fractions depending on starting microstructure after intercritical annealing $(\%)$

\begin{tabular}{|c|c|c|c|c|c|c|c|c|c|c|c|c|c|c|c|}
\hline \multirow{2}{*}{ Starting microstructure } & \multicolumn{15}{|c|}{ Intercritical annealing temperature $\left({ }^{\circ} \mathrm{C}\right)$} \\
\hline & 720 & 725 & 730 & $\underline{740}$ & 750 & $\underline{760}$ & 770 & $\underline{780}$ & 790 & $\underline{800}$ & 810 & 820 & 830 & $\underline{840}$ & 850 \\
\hline Ferrite-pearlite & - & - & 27.2 & 29.9 & 30 & 35.3 & 40.7 & 49.8 & 57.1 & 58.1 & 62.2 & 62.9 & 70.9 & 79.2 & 82.4 \\
\hline Martensite & - & - & - & 14.2 & 18.8 & 29.8 & 31.3 & 35.7 & 42.4 & 50.9 & 51.8 & 62.5 & 71.7 & 81.2 & 86.1 \\
\hline
\end{tabular}

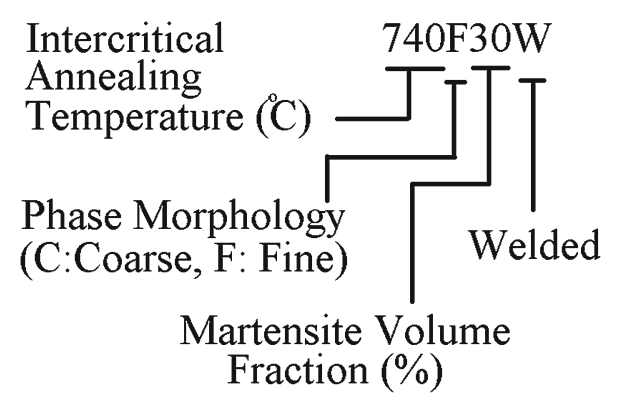

Fig. 2. Coding of experimental parameters.

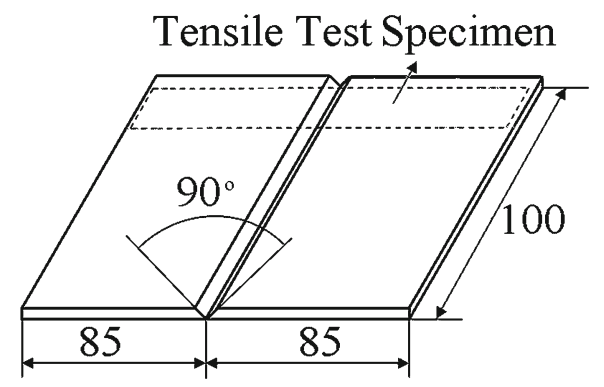

\section{$\mathrm{t}: 4 \mathrm{~mm}$}

Fig. 3. Geometrical dimensions of St37 sheets joined by MAG welding.

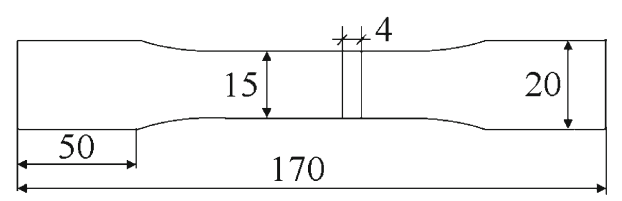

Fig. 4. Geometry and dimensions of the tensile test sample [15].
Tensile test specimens were prepared according to ASTM E-8M [16]. Welded specimens were also tested using test pieces with a weld in the middle lying perpendicular to tensile direction. The dimension and the geometry of tensile specimens can be seen in Fig. 4 . Shimadzu AG/IS $(100 \mathrm{kN})$ universal tensile tester was employed for tensile testing operations. Three test readings were taken and an average was computed for each set of specimens.

\subsection{Micro hardness test}

The hardness of the welded specimens was measured on the cross-sections using a Shimadzu HMV-2 Vickers indenter with a $100 \mathrm{~g}$ load.

\section{Results and discussion}

\subsection{Heat treatments, welding and microstructures}

Following heat treatment of both specimens with coarse and fine microstructure, it is shown that a DP steel microstructure was clearly obtained. The martensite volume fractions (MVF) for all specimens after intercritical heat treatment are given in Table 3 . The heat treatment temperatures underlined in Table 3 are heat treatment temperatures producing similar volume fractions, given in bolt, that were achieved in specimens with starting microstructure of ferrite + pearlite and martensite after intercritical heat treatment. Microstructures of these specimens are given in Fig. 5.

Two different starting microstructures were obtained before the intercritical annealing by subjecting the specimens to full annealing and quenching from the austenite zone. The starting microstructure is the 

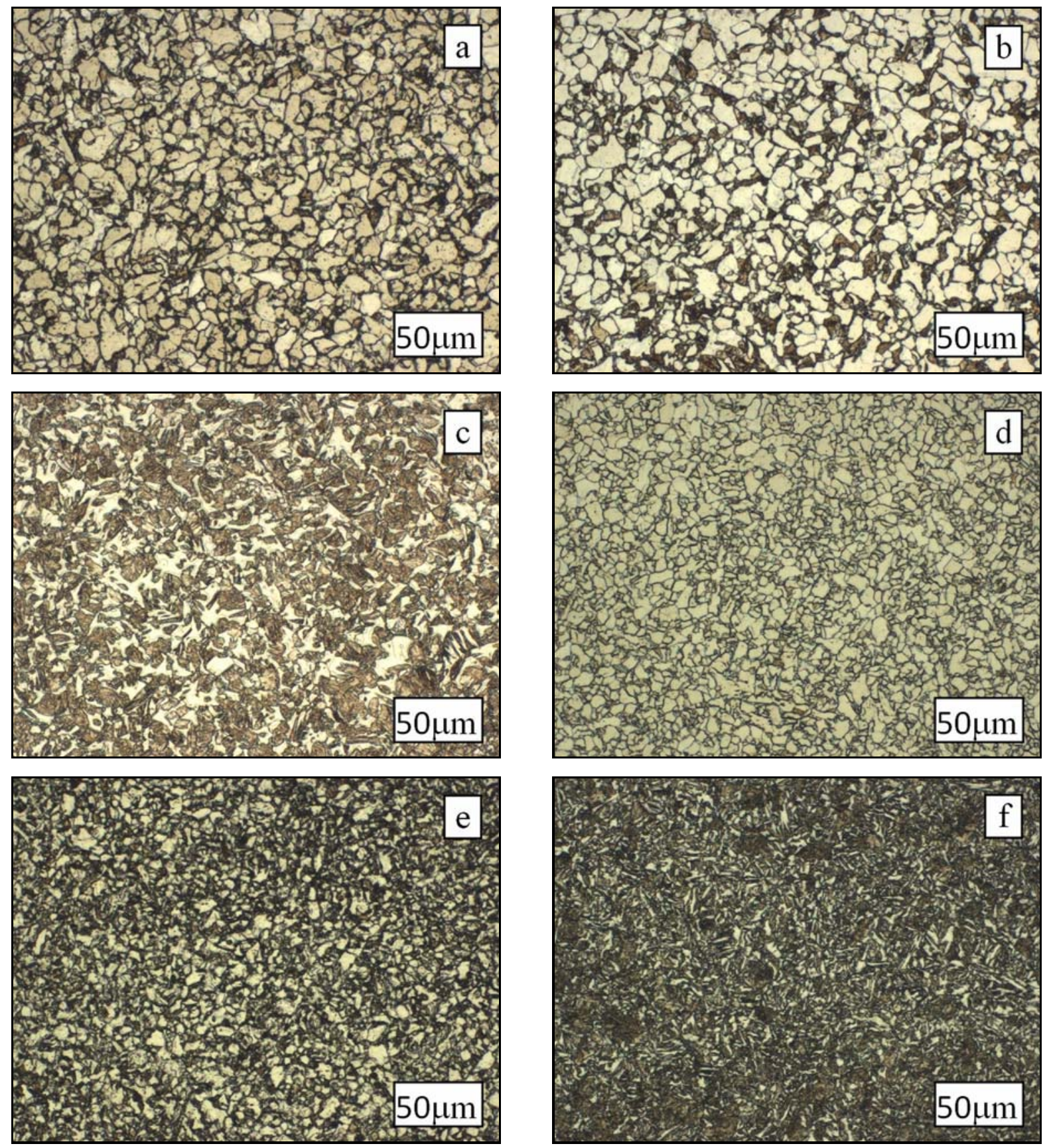

Fig. 5. Microstructures of specimens: (a) 740C30, (b) 780C50, (c) 840C80, (d) 760F30, (e) 800F50, (f) 840F80. Dark and light regions are martensite and ferrite, respectively.

microstructure which the steels have before the intercritical annealing. Depending on the starting microstructure, the phase morphology, grain sizes and the mechanical properties of the DP steels change. As a result of full annealing, the microstructure is composed of ferrite + pearlite and as a result of quenching, the microstructure is composed of martensite. After intercritical heat treatments, the starting microstructure with ferrite + pearlite was coarse dispersed ferrite + martensite grains, while the starting microstructure with martensite was fine dispersed ferrite
+ martensite grains. Similar results were also reported by some researchers [17-21]. Average grain sizes of $22,27,23,17,14,12 \mu \mathrm{m}$ for the specimens $740 \mathrm{C} 30$, 780C50, 840C80, 760F30, 800F50, 840F80 were obtained, respectively. Respective average grain sizes for each zone, base metal (BM), HAZ and WM are given in Table 4. Martensite appears in darker colour in Fig. 5 compared to ferrite in gray. WM microstructures of specimens are given in Figs. 6, 7.

In HAZ, the fine grained DP steel contained average grain sizes ranging from 7.7 to 8.9 micron and 


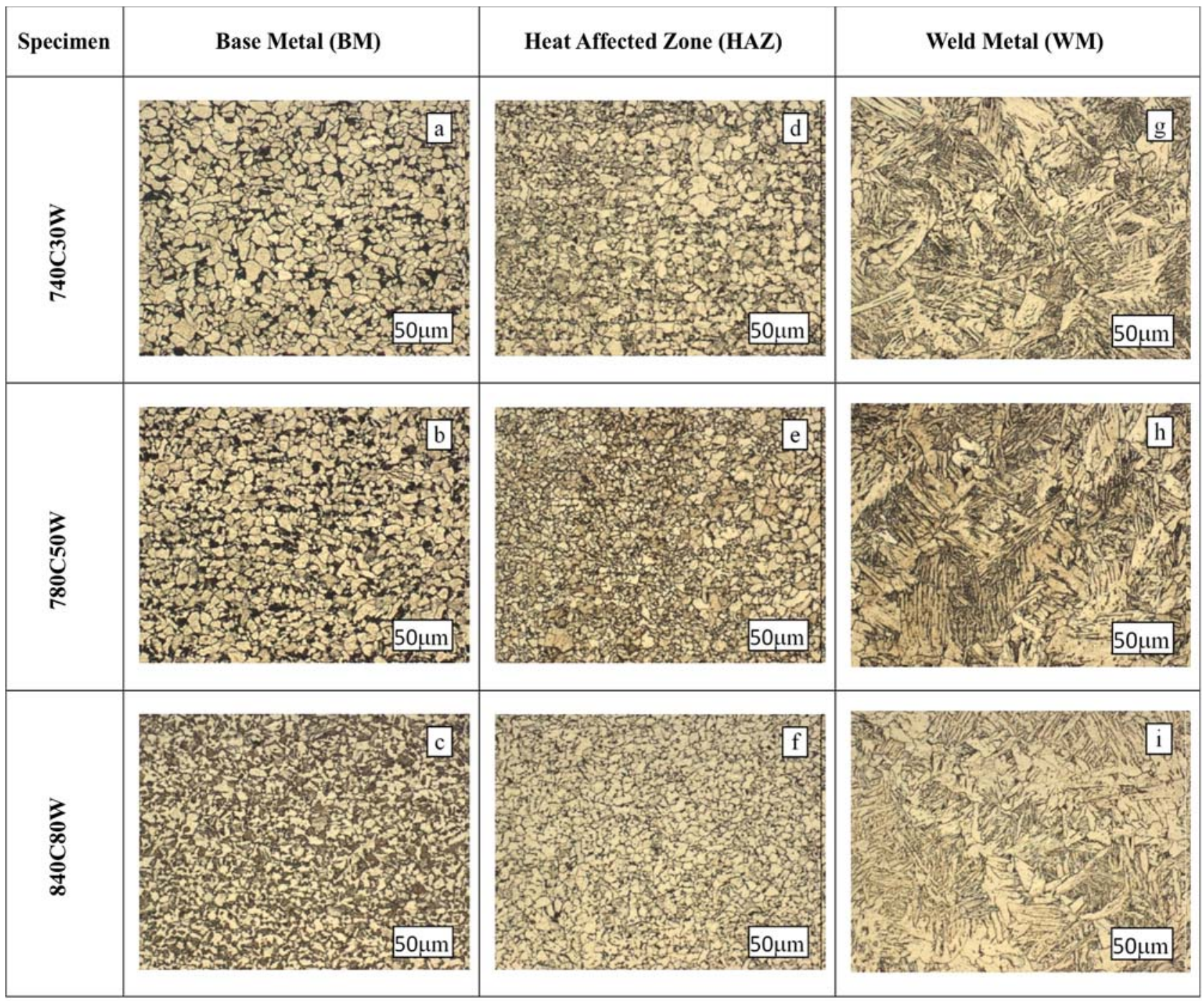

Fig. 6. Weld zone microstructures for specimens with coarse dispersed ferrite and martensite.

Ta ble 4. Average grain sizes $(\mu \mathrm{m})$ in different zones of the welds

\begin{tabular}{lcrr}
\hline Specimen & BM & HAZ & \multicolumn{1}{c}{ WM } \\
\hline $740 \mathrm{C} 30 \mathrm{~W}$ & $22 \pm 1$ & $17.1 \pm 3$ & $73 \pm 8$ \\
$780 \mathrm{C} 50 \mathrm{~W}$ & $27 \pm 1$ & $9.3 \pm 3$ & $54 \pm 12-66 \pm 9$ \\
$840 \mathrm{C} 80 \mathrm{~W}$ & $23 \pm 1$ & $8.8 \pm 2$ & $112 \pm 12-53 \pm 9$ \\
$760 \mathrm{~F} 30 \mathrm{~W}$ & $17 \pm 1$ & $8.9 \pm 1$ & $63 \pm 6-58 \pm 5$ \\
$800 \mathrm{~F} 50 \mathrm{~W}$ & $14 \pm 1$ & $8.3 \pm 1$ & $52 \pm 3-67 \pm 7$ \\
$840 \mathrm{~F} 80 \mathrm{~W}$ & $12 \pm 1$ & $7.7 \pm 1$ & $225 \pm 15-84 \pm 6$ \\
\hline
\end{tabular}

WM grain size was dominantly in the columnar form which was represented by two different numbers as given in Table 4. Grain sizes in weld metals appear to be higher than those of HAZ grains.

Compared to $740 \mathrm{C} 30 \mathrm{~W}-\mathrm{HAZ}, 780 \mathrm{C} 50 \mathrm{~W}-\mathrm{HAZ}$ and $840 \mathrm{C} 80 \mathrm{~W}-\mathrm{HAZ}$ microstructures of HAZ, it is observed that the microstructure of $740 \mathrm{C} 30 \mathrm{~W}-\mathrm{HAZ}$ is coarser in appearance. The microstructure of $740 \mathrm{C} 30 \mathrm{~W}-\mathrm{WM}$, similar to its HAZ microstructure, has an appearance of columnar grains containing a refined intragranular irregularly distributed acicular structure. In all microstructures, grain boundaries are decorated with grain boundary ferrite along with Widmänstatten formation. This is clearly shown in Fig. 7. It is seen in the figure that specimen coded WM causes that starting microstructure of weld metal has a strong influence on the final microstructure which is characterized by its refined appearance containing relatively 


\begin{tabular}{|c|c|c|c|}
\hline Specimen & Base Metal (BM) & Heat Affected Zone (HAZ) & Weld Metal (WM) \\
\hline 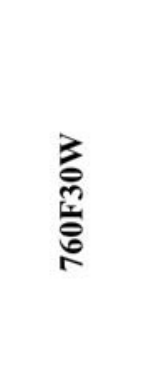 & 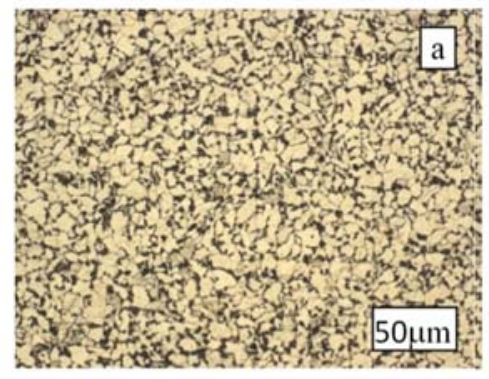 & 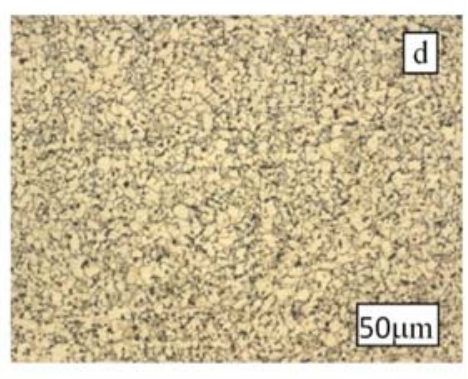 & \\
\hline 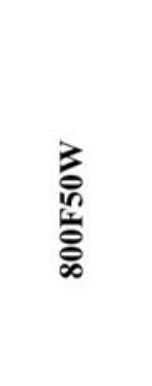 & 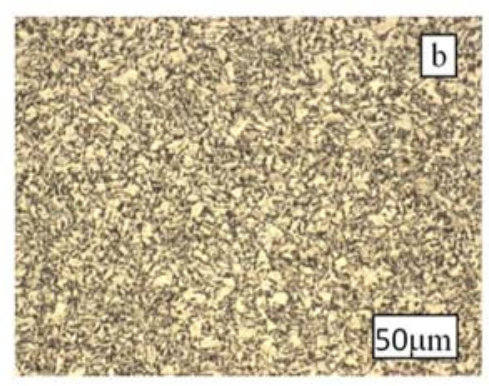 & 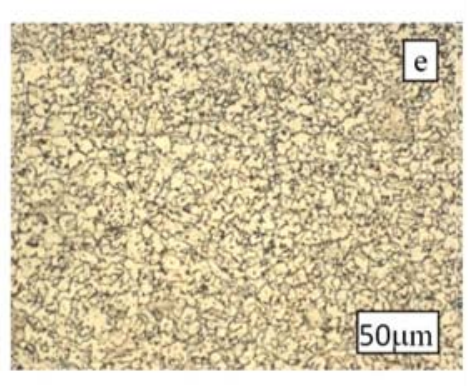 & \\
\hline 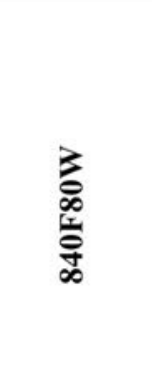 & 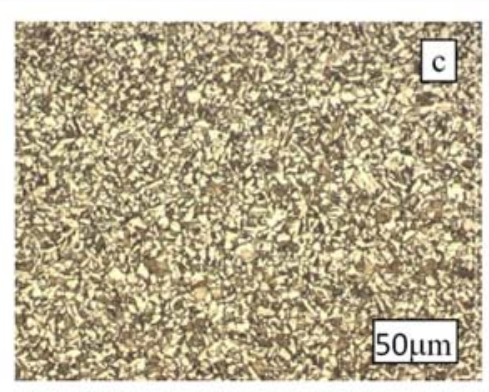 & 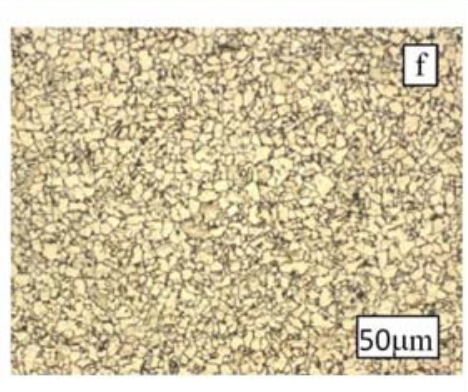 & \\
\hline
\end{tabular}

Fig. 7. Weld zone microstructures for specimens with fine dispersed ferrite and martensite.

higher percentage of martensite. HAZ microstructures in Fig. 6 (740C30W-BM, 780C50W-BM, 840C80W-BM and 740C30W-HAZ, 780C50W-HAZ, 840C80W-HAZ) vary significantly as oppose to the microstructure of critical cooling zone which has similar grain structure as with WM. This may suggest that the grain growth is restricted by this behaviour. However, acicular microstructure may be obtained by the formation of long and large columnar grains which is affected by the excessive grain growth induced by the coarsening of refined intragranular structure.

The small grain size within the WM appears to result in a chaotic structure with an appearance of ferrite + cementite side plates containing small fraction of retained austenite and/or martensite. Similar systematic formation is also seen in Fig. 7. The weld metal of DP steel with a starting microstructure of martensite ended up with a finer intragranular microstructure, while after the welding the starting coarse microstructure such as pearlite with large grain might result in a coarser microstructure in HAZ. In addition, for specimens shown in Fig. 7, there is an indication of excessive grain growth. These microstructures usually appear in steel with low alloying contents or decarburization of steel. It is obvious that very fine inner grain morphology of ferrite + cementite side plates requires large quantity of $\mathrm{C}$ for the formation of fine cementite plates, leaving grain boundaries poor of $\mathrm{C}$, and therefore resulting in the formation of large grains.

\subsection{Tensile test results}

Tensile test results are given in Table 5. As shown in Table 5, the yield strength of the $\mathrm{F}$ series (fine grain) DP steels is generally higher than that of the $\mathrm{C}$ series (coarse grain) DP steels. The yield strength in non welded specimens increased with increasing MVF. This result is due to the matrix structure of the specimens being composed of martensite rather than of ferrite. Similar situation was also seen in tensile strength 
Table 5. Tensile test results

\begin{tabular}{|c|c|c|c|}
\hline Specimen & Yield strength (MPa) & Ultimate tensile strength $(\mathrm{MPa})$ & Elongation (\%) \\
\hline $740 \mathrm{C} 30$ & 368.2 & 560.2 & 16 \\
\hline $780 \mathrm{C} 50$ & 381.5 & 638.4 & 17 \\
\hline $840 \mathrm{C} 80$ & 423.2 & 668.5 & 19 \\
\hline 760F30 & 377.8 & 604 & 20 \\
\hline $800 \mathrm{~F} 50$ & 391.5 & 616 & 18 \\
\hline $840 \mathrm{~F} 80$ & 469.8 & 683.2 & 19 \\
\hline $740 \mathrm{C} 30 \mathrm{~W}$ & 277.1 & 327.9 & 7 \\
\hline 780C50W & 302.5 & 360.7 & 6 \\
\hline $840 \mathrm{C} 80 \mathrm{~W}$ & 335.7 & 425.2 & 9 \\
\hline $760 \mathrm{~F} 30 \mathrm{~W}$ & 231.7 & 279.3 & 5 \\
\hline $800 \mathrm{~F} 50 \mathrm{~W}$ & 267.1 & 327.2 & 5 \\
\hline $840 \mathrm{~F} 80 \mathrm{~W}$ & 304.3 & 343.1 & 5 \\
\hline As obtained & 221 & 362 & 17 \\
\hline
\end{tabular}

of non welded specimens, which was also observed by some researchers [22-25]. In addition, the yield strength of non welded specimens changed inversely with the change in average grain size in accordance with Hall-Petch law [26, 27]. With increasing MVF values, yield strength and tensile strength of series $\mathrm{F}$ and $\mathrm{C}$ after welding also increased, but elongation did not change. MVF in welds with $\mathrm{F}$ and $\mathrm{C}$ specimens yield and ultimate tensile strength increased, however, tensile elongation values did not change. The average grain size in HAZ may have an effect on the plastic deformation stage. Welds with $\mathrm{F}$ specimens produced lower yield and ultimate tensile strength compared to $\mathrm{C}$ series specimens. The improved performance of $\mathrm{C}$ series specimens may be originating from crack deflection capability through ferrite side plate islands in coarse grains which is not effectively achieved in small grains. The elongations in all welds are generally lower in values of which the types of microstructures are thought to be of prime importance as seen in Table 4 . $840 \mathrm{C} 80 \mathrm{~W}$ appears to be an ideal specimen in terms of tensile tests.

\subsection{Hardness of weld zone}

Hardness variation in weld zones may indicate the formation of hard or soft regions whereby structural changes occur. However, as seen in Table 6, the hardness of parent metal is higher than those of other parts of weld zone due to probably having a varying fraction of martensite in microstructure, whereas $\mathrm{HAZ}$ and WM are subjected to heat effect and therefore do not contain martensite. The microstructural study also showed that parent metal in all the specimens had fine grains compared to WM and although slightly lower values than those of HAZ. As seen in Table 6, the hardness of WM is higher compared to HAZ even though the grain size is comparatively larger. This may suggest that the initial microstructure does not have a substantial influence on the hardness.
Ta b l e 6. Average micro-hardness values, HV100, for each section of the weld zone

\begin{tabular}{lccc}
\hline Specimen & BM & HAZ & WM \\
\hline $740 \mathrm{C} 30 \mathrm{~W}$ & 197.8 & 160.4 & 198.5 \\
780C50W & 205.5 & 152.7 & 163.6 \\
840C80W & 195.8 & 155.0 & 145.0 \\
760F30W & 184.3 & 145.0 & 173.6 \\
800F50W & 199.4 & 167.7 & 168.0 \\
840F80W & 197.0 & 149.3 & 184.0 \\
\hline
\end{tabular}

\section{Conclusions}

The results obtained in this study are summarized as follows:

- Intercritical annealing produced DP microstructure in St 37 steel.

- The two different starting microstructures that were obtained prior to intercritical annealing led to coarse and fine dispersions of ferrite and martensite in the microstructures.

- The MVF increased with increasing intercritical annealing temperature.

- The weld metal of DP steel with a starting microstructure of martensite ended up with a finer intragranular microstructure while after the welding of coarse starting microstructure such as pearlite in large grain may result in a coarser microstructure in HAZ.

- The strength and ductility properties of the finedispersed non welded specimens that were subjected to intercritical annealing exhibited better results than the non welded coarse-dispersed specimens.

\section{Acknowledgement}

A section of this paper was presented at the 2nd International Conference on Welding Technologies and Exhibition 2012 in Turkey. 


\section{References}

[1] Palaniswamy, H., Al-Nasser, A.: Forming of Advanced High-Strength Steels (AHSS). Sheet Metal Forming Processes and Applications. Material Park, ASM International 2012.

[2] http://www.autosteel.org/ /media/Files/Autosteel/ Programs/ULSAB-AVC/avc_ttd6.pdf (accessed 27 September 2013)

[3] Bleck, W.: J. Minerals, 48, 1996, p. 26.

[4] Chen, D. L., Wang, Z. G., Jiang, X., Ai, S. H., Shih, C. H.: Mater. Sci. Eng. A, 108, 1989, p. 141. doi:10.1016/0921-5093(89)90415-2

[5] Mediratta, S. R., Ramaswamy, V., Singh, V., Rama Rao, P.: Trans. Indian Inst. Metals, 38, 1985, p. 350.

[6] Bhadeshia, H. K. D. A.: Scripta Metal., 17, 1983, p. 857. doi:10.1016/0036-9748(83)90249-1

[7] Byun, T. S., Kim, I. S.: J. Mater. Sci., 28, 1993, p. 2923. doi:10.1007/BF00354695

[8] Davies, R. G.: Metall. Trans. A, 10, 1979, p. 113. doi:10.1007/BF02686414

[9] Ulu, S., Kayali, Y., Gunes, I.: Mater. Sci. Tech., 29, 2013, p. 255. doi:10.1179/1743284712Y.0000000126

[10] Beynon, N. D., Oliver, S., Jones, T. B., Fourlaris, G.: Mater. Sci. Tech., 21, 2005, p. 771. doi:10.1179/174328405X41038

[11] Yia, H. L., Ghusha, S., Bhadeshia, H. K. D. H.: Mat. Sci. Eng. A, 527, 2010, p. 4870. doi:10.1016/j.msea.2010.04.022

[12] Carry, H. B., Helzer, S. C.: Modern Welding Technology. 5th edition. New Jersey, Pearson Education Inc. 2005.

[13] Zhang, X. Y., Zhang, Y. S., Chen, G. L.: Key. Eng. Mater., 353-358, 2007, p. 1597.
[14] Adolfsson, S., Bahrami, A., Bolmsj, G., Claesson, I.: Weld. Res. Suppl., 78, 1999, p. 59.

[15] Serope, K., Steven, S.: Manufacturing Engineering and Technology. 8th edition. Upper Saddle River, Prentice Hall 2001.

[16] ASTM E8/E8M-11 Standard Test Methods for Tension Testing of Metallic Materials. West Conshohocken, ASTM International 2011. doi:10.1520/E0008_E0008M

[17] Priestner, R., Ajmal, M.: Mater. Sci. Tech., 3, 1987, p. 360. doi:10.1179/mst.1987.3.5.360

[18] Priestner, R.: In.: Proceedings of Conference of Phase Transformations 87. Ed.: Lorimer, G. W. Cambridge, Institute of Metals 1987, p. 411.

[19] Erdogan, M.: Scripta Metal., 48, 2003, p. 501. doi:10.1016/S1359-6462(02)00500-6

[20] Gordion, L., Muttteazzi, P., Tiziani, A., Zambon, A.: Mat. Sci. Eng. A-Struct., 31, 1991, p. 215. doi:10.1016/0921-5093(91)90397-6

[21] Yong, D. Z., Brown, E. L., Matlock, D. K., Krauss, G.: Metall. Mater. Trans. A, 8, 1985, p. 1523. doi:10.1007/BF02658685

[22] Davies, R. G.: Metall. Trans. A, 18, 1978, p. 671. doi:10.1007/BF02659924

[23] Kim, N. J., Thomas, G.: Metall. Trans. A, 12, 1981, p. 483. doi:10.1007/BF02648546

[24] Erdogan, M.: Bauschinger and Tensile Properties of Dual-Phase Steels. [PhD. Thesis]. Manchester, The Manchester University 1993.

[25] Tomita, Y.: J. Mater. Sci. Lett., 25, 1990, p. 179.

[26] Hall, E. O.: Proceed. of the Phys. Soc. of London, B64, 1951, p. 747. doi:10.1088/0370-1301/64/9/303

[27] Petch, N. J.: J. the Iron and Steel Ins., 174, 1953, p. 25. 